\title{
Reply to: methotrexate administration directly into the fourth ventricle in children with malignant fourth ventricular brain tumors: a pilot clinical trial
}

\author{
Ian J. Cohen ${ }^{1}$ (B)
}

Received: 3 November 2015/ Accepted: 30 December 2015/Published online: 5 January 2016

(C) Springer Science+Business Media New York 2016

To the Editor,

Dear sir, we were very pleased to read the article: methotrexate administration directly into the fourth ventricle in children with malignant fourth ventricular brain tumors: a pilot clinical trial [1] in the journal and consider it an example of how a clinical study should be conducted. The damage caused by surgery to the floor of the fourth ventricle renders complete surgical resection contraindicated and the idea of substituting intraventricular methotrexate for complete resection is an attractive alternative. The disadvantage of leaving residual tumor has been turned into an advantage here by the use of imaging to assess the effect of therapy. The insertion of the treatment catheter by direct vision at the time of surgery prevented the problems caused when lateral ventricle catheters are placed blindly through cerebral cortex, that may cause both catheter malposition and cerebral hemorrhage, also, some catheter holes may be within the ventricle and others within the cerebral cortex and so infusions may force the infused agent into brain parenchyma, contributing to leukoencephalopathy. Free flow of the csf was determined by CINE MRI and isotope studies. The authors have appreciated the importance of neuropsychological assessment before and after the therapy and found that csf methotrexate levels of 3.18 micromol/L, (range $0.53-212.36 \mathrm{micromol} / \mathrm{L}$ ) had been achieved for at least $24 \mathrm{~h}$. The partial clinical response was encouraging and they wish to perform future studies to explore the safety

Ian J. Cohen

icohen@tau.ac.il

1 Sackler Faculty of Medicine Tel Aviv University, Ramat Aviv, Israel and efficacy of higher doses of methotrexate. Caution would be advised since although no neuropsychological damge was found at this dose of methotrexate, use of a higher dose that will result in increased diffusion of methotrexate into tumor will also cause the same effect in normal brain parenchyma. I would strongly suggest that any future study should at least randomize the patients with a group treated with high dose MTX and appropriate dose folinic acid. This therapy can achieve similar csf levels but the tissue levels will be higher than those achieved by diffusion of methotrexate from the csf. When IV methotrexate is given with adequate fluids and bicarbonate and the rescue is started by $36 \mathrm{~h}$ no neurotoxicity is expected to be found if the dose of folinic acid is adequate [2]. We would suggest a dose of $760 \mathrm{mg}$ folinic acid after $12 \mathrm{~g} / \mathrm{m}^{2}$ MTX. The concept of "over" rescue has be discredited and should not deter the use of this valuable non toxic approach [3].

\section{References}

1. Sandberg DI, Rytting M, Zaky W, Kerr M, Ketonen L, Kundu U, Bartlett D, Moore BL, Yang G, Hou P, Sitton C, Cooper LJ, Gopalakrishnan V, Lee DA, Thall PF, Khatua S (2015) Methotrexate administration directly into the fourth ventricle in children with malignant fourth ventricular brain tumors: a pilot clinical trial. J Neurooncol 125:133-141

2. Cohen IJ, Wolff JE (2014) How long can folinic acid rescue be delayed after high-dose methotrexate without toxicity. Pediatr Blood Cancer 61:7-10

3. Cohen IJ (2013) Challenging the clinical relevance of folinic acid over rescue after high dose methotrexate (HDMTX). Med Hypotheses 31:942-947 